\title{
Identification of an Axotomy-Induced Glycosylated Protein, AIGP1, Possibly Involved in Cell Death Triggered by Endoplasmic Reticulum-Golgi Stress
}

\author{
Shunsuke Aoki, ${ }^{1,2}$ Qingning Su, ${ }^{3}$ Hang Li, ${ }^{1}$ Kaori Nishikawa, ${ }^{1,2}$ Kohichi Ayukawa, ${ }^{1}$ Yoko Hara, ${ }^{1}$ \\ Kazuhiko Namikawa, ${ }^{3}$ Sumiko Kiryu-Seo, ${ }^{3}$ Hiroshi Kiyama, ${ }^{3}$ and Keiji Wada ${ }^{1}$ \\ ${ }^{1}$ Department of Degenerative Neurological Diseases, National Institute of Neuroscience, NCNP, Kodaira, Tokyo 187- \\ 8502, Japan, 2Japan Science and Technology Corporation, Kawaguchi, Saitama 332-0012, Japan, and ${ }^{3}$ Department of \\ Anatomy, Graduate School of Medicine, Osaka City University, Asahimachi, Abenoku, Osaka 545-8585, Japan
}

\begin{abstract}
We developed a new method, designated N-linked glycosylation signal (NGS) differential display (DD)-PCR, that enables the identification of genes encoding $\mathrm{N}$-linked glycosylated molecules that exhibit varying patterns of expression. Using this innovative technique, we identified an $\mathrm{N}$-linked glycosylated 11-transmembrane domain protein that is upregulated in response to axotomy. Expression levels increased $3 \mathrm{~d}$ after axotomy, reached maximal levels at approximately postoperative days $5-7$, and then gradually decreased through day 20 . The protein was termed axotomy-induced glycosylated/Golgicomplex protein 1 (AIGP1). AIGP1 immunoreactivity is specifically localized in neurons, with subcellular localization within the Golgi, indicating that AIGP1 is a resident Golgi protein.
\end{abstract}

Moreover, AIGP1 gene expression in cultured neurons is specifically induced by the endoplasmic reticulum (ER)-Golgi stressors tunicamycin and brefeldin A. We observed that the frequency of cell death is increased by AIGP1 overexpression and that the corresponding region of the protein implicated in the activity involves the large eighth and ninth transmembrane loops. Our results suggest that AIGP1 gene activation and protein accumulation in the Golgi complex in response to axotomy-induced ER-Golgi stress may contribute to signaling during programmed cell death in damaged neurons.

Key words: axotomy; Golgi complex; glycoprotein; stress; nerve regeneration; cell death
Injuries to peripheral nerves in the adult mammal activate regeneration signals that lead to neuronal survival and axonal elongation (Persson and Ibanez, 1993; Snider, 1994; Oppenheim, 1996; Fu and Gordon, 1997; Pettmann and Henderson, 1998; Goldberg and Barres, 2000). This regenerative potential of the peripheral nervous system (PNS) is distinct from that of the adult CNS, in which most neurons do not regenerate and subsequently die after injury (Fu and Gordon, 1997; Goldberg and Barres, 2000). Elucidation of the molecular basis of this difference between the PNS and CNS would significantly contribute to rescue in diseases that affect the CNS. Axotomy, a well characterized model of nerve injury, is useful for studies on molecular and cellular mechanisms of nerve regeneration and death. For several years, we attempted to isolate molecules with expression patterns that are altered by axotomy, with the goal of identifying those that participate in neuronal death and regeneration. For this purpose, we performed differential display (DD)-PCR screening and expressed sequence tag (EST) analysis procedures, which allowed the identification of various classes of molecules that are upregulated or downregulated in response to axonal damage (Kiryu et al., 1995; Kitahara

\footnotetext{
Received March 15, 2002; revised Sept. 23, 2002; accepted Sept. 25, 2002.

This study was supported in part by grants from the Ministry of Health, Labor and Welfare of Japan, the Ministry of Education, Science, Technology, Sports and Culture, and the Japan Science and Technology Corporation. We are grateful to M. Ohara and Prof. M. Sato (Fukui Medical University) for helpful comments.

Correspondence should be addressed to either of the following: Dr. Keiji Wada, Department of Degenerative Neurological Diseases, National Institute of Neuroscience, NCNP, Kodaira 4-1-1, Tokyo 187-8502, Japan, E-mail: wada@ncnp.go.jp; or Dr. Hiroshi Kiyama, Department of Anatomy, Graduate School of Medicine, Osaka City University, Asahimachi, Abenoku, Osaka 545-8585, Japan, E-mail: kiyama@med.osaka-cu.ac.jp.

Copyright (C) 2002 Society for Neuroscience $0270-6474 / 02 / 2210751-10 \$ 15.00 / 0$
}

et al., 1995; Morita et al., 1996; Namikawa et al., 1998; Tanabe et al., 1999; Kiryu-Seo et al., 2000; Namikawa et al., 2000; Tanabe et al., 2000). Although these studies revealed that a significant number of intracellular molecules are implicated in the nerve regeneration process, the involvement of membrane-bound glycoproteins has not been well established. However, the possible involvement of a glycosylated membrane protein in neuronal survival and regeneration was suggested by our previous work using lectin histochemistry to visualize glycosylated proteins in injured neurons (Ohshige-Hayashi and Kiyama, 1997). Among 16 lectins, only Glycine max (soybean agglutinin)-binding activity was selectively increased in injured neurons after hypoglossal nerve axotomy. Further electron microscopy observations revealed that Glycine max binding is localized to the Golgi complex in injured motoneurons as well as in the extracellular space between neurons and microglia. Other lectin histochemistry studies demonstrated that specific and selective changes in Glycine max staining are apparent in transected dorsal root ganglia (Plenderleith et al., 1988; Cameron et al., 1991; Shortland et al., 1999). In a motor neuron disorder in which subacute motor neuropathy is associated with neoplastic angioendotheliosis, very intense Glycine max staining was also observed in patients' motoneurons (Nagao et al., 1994). However, the identities of these glycosylated proteins, which were elevated in response to neuronal injuries in Golgi or the cell surface, remain unknown because of limitations imposed by their low levels of expression.

We developed a novel method to screen for glycosylated molecules having varying gene expression patterns. Degenerate primers corresponding to the consensus nucleotide sequence of the $\mathrm{N}$-linked glycosylation signal (NGS) were used in DD-PCR. Us- 
Figure 1. Isolation of a gene encoding an N-linked glycosylated protein from axotomized hypoglossal nuclei by NGS DD-PCR. $A$, The primer sequence used in NGS DD-PCR $(N=$ random nucleotide). $B,{ }^{35}$ S-labeled PCR products (from NGS DD-PCR) in hypoglossal nuclei from normal (cont) and operated (op.) sides (7 d after injury). The arrowhead indicates the band in the op. lane corresponding to a differentially expressed gene. $C$, Expression of the isolated cDNA fragment was further examined by in situ display. A section was obtained from a mouse $7 \mathrm{~d}$ after it had undergone unilateral hypoglossal nerve transection. The arrow in the top panel indicates increased expression of the candidate gene on the injured/right side only. A bright-field micrograph of Nissl stain shows localization of mRNA on neurons in the hypoglossal nucleus (bottom). Scale bar: top, $2 \mathrm{~mm}$; bottom, 50 $\mu \mathrm{m} . D$, mRNA expression profile after hypoglossal nerve transection. mRNA signal intensity in control $(\bigcirc)$ and operated sides (๑) was measured and presented as mean \pm SD obtained from at least eight sections from five mice; ${ }^{*} p<0.01$ (ANOVA). $E$, AIGP1 is an N-linked glycosylated protein. COS-7 cells were transfected with a negative control mock construct (lanes 1,2) or N-terminal FLAG-tagged AIGP1 expression construct (lanes 3, 4, 5). Cell lysates were treated without (lanes 1, 3, 4) or with (lanes 2, 5) $5 \mathrm{U} / \mathrm{ml} N$-glycosidase F and subjected to SDS-PAGE (10 $\mu \mathrm{g}$ protein per lane). Lysates from PC12 cells were treated without (lanes 6,7) or with (lane 8) $5 \mathrm{U} / \mathrm{ml} \mathrm{N}$-glycosidase F and subjected to SDS-PAGE (30 $\mu \mathrm{g}$ protein per lane). Blots were probed with an antibody to AIGP1 (ABEP56). Cell lysates not subjected to $0.5 \%$ Nonidet P-40 treatment were analyzed by Western blot (lanes 3, 6). The results are representative of three separate experiments that yielded similar results.

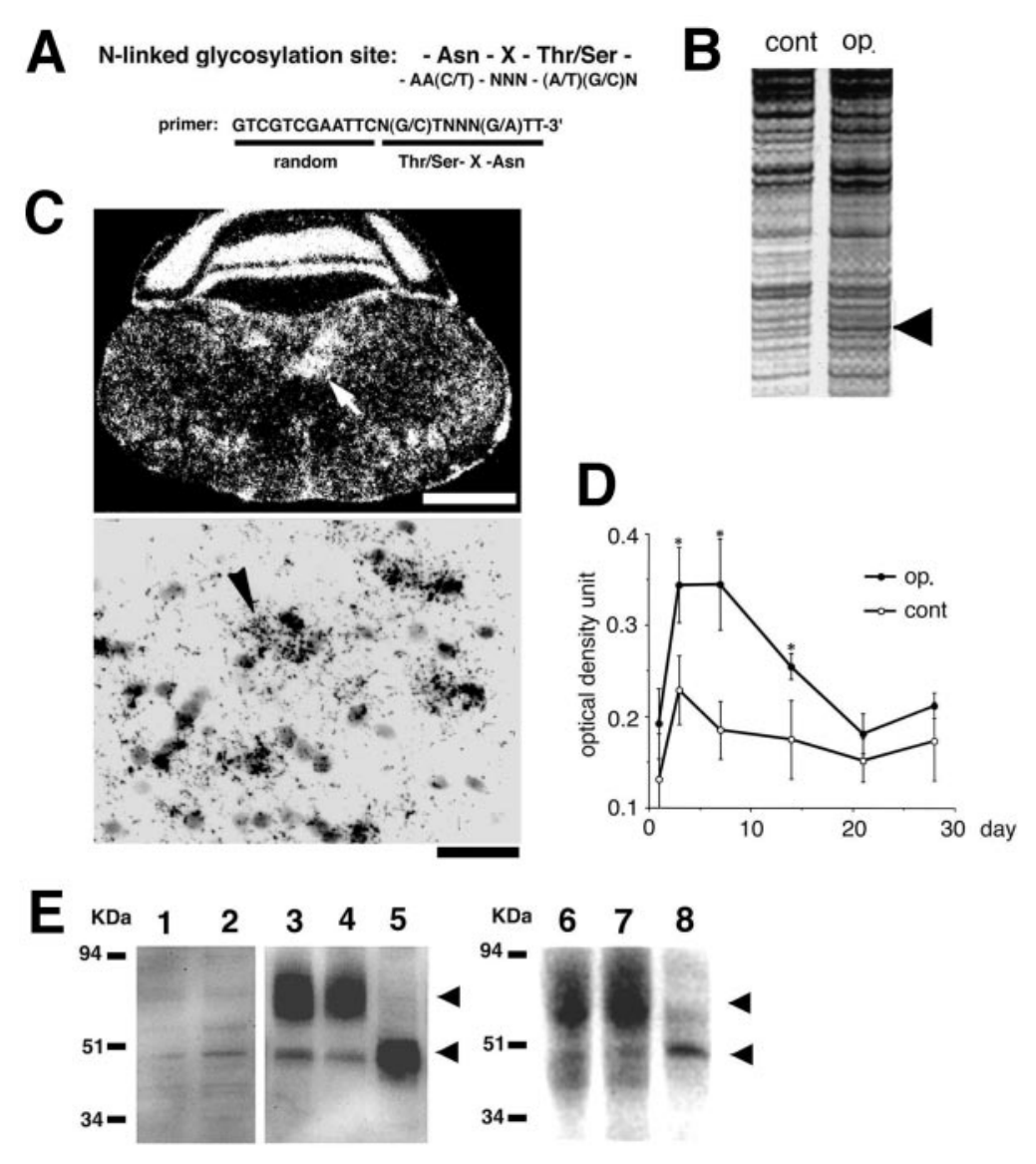

ing the model of hypoglossal nerve axotomy in mice (Kiryu et al., 1995), the NGS DD-PCR procedure identified an N-linked glycosylated protein whose expression is upregulated in response to axotomy. This protein, designated axotomy-induced glycosylated/ Golgi-complex protein 1 (AIGP1), contains 11 putative transmembrane domains and localizes to the Golgi complex in neurons. We address the functional significance of AIGP1 and suggest that this glycoprotein may be involved in programmed cell death signaling triggered by axotomy.

\section{MATERIALS AND METHODS}

Antibodies and reagents. Monoclonal and polyclonal antibodies were as follows: anti-Myc 9E10 (Santa Cruz Biotechnology, Santa Cruz, CA), anti-FLAG M2 (Sigma, St. Louis, MO), anti-Tau1 (Chemicon International, Temecula, CA), anti-Map2 (Chemicon International), antisynapsin I (Synaptic Systems, Göttingen, Germany), anti-TGN46 (Cosmobio, Tokyo, Japan), anti- $\beta$-galactosidase (Promega, Madison, WI), and anti-membrin (Calbiochem, San Diego, CA). All secondary polyclonal antibodies conjugated to Alexa Fluor fluorescein were purchased from Molecular Probes (Eugene, OR). Staurosporine (STS), cytochalasin D, and brefeldin A (all from Sigma) were dissolved in DMSO to 100 $\mu \mathrm{M}, 100 \mu \mathrm{M}$, and $1 \mathrm{mg} / \mathrm{ml}$, respectively. Tunicamycin (Sigma) was 1 $\mathrm{mg} / \mathrm{ml}$ in $0.1 \mathrm{~N} \mathrm{NaOH}$.

Animal surgery. Hypoglossal nerve transection was performed as described (Kiryu et al., 1995), using C57BL/6J mice weighing $\sim 20$ gm. Briefly, the right hypoglossal nerve of each mouse was cut with scissors and hypoglossal nuclei from both the operated and normal (contralateral) sides were dissected $7 \mathrm{~d}$ after the surgery. For differential display, 90 hypoglossal nuclei each (operated and normal) were collected, placed in liquid nitrogen, and stored at $-80^{\circ} \mathrm{C}$ until use. For in situ hybridization, five mice were killed per day on postoperative days $1,3,7,14,21,28$, and 35. All animal experiments were performed according to NIH Standards for Treatment of Laboratory Animals.

$N$-glycosylation sequence differential display-PCR. Unilateral hypoglossal nerves of 90 male mice were transected, and the hypoglossal nuclei from both control and operated sides were dissected under a microscope. Total RNA was purified from operated and normal hypoglossal nuclei, and the RNA from each nucleus $(0.2 \mu \mathrm{g})$ was treated with DNase I and reverse-transcribed to yield cDNA using the oligodeoxynucleotide $\mathrm{dT}_{18}$ and Superscript reverse transcriptase (Invitrogen, Rockville, MD). Onetenth of the cDNA was amplified by PCR using a single primer (5'GTCGTCGAATTCN(G/C)TNNN(G/A)TT-3') containing a $5^{\prime}$ sequence (12 nucleotides) randomly selected among 87 arbitrary primers used in general DD-PCR, and a $3^{\prime}$ sequence (9 nucleotides) corresponding to the $\mathrm{N}$-glycosylation signal, Asn-X-Thr/Ser. This single primer (see Fig. $1 A$ ) was designed to hybridize specifically to the target NGS-reverse sequence on the lower site of one template strand, and also to hybridize randomly to the upper site of the other template strand (as in DD-PCR). The following PCR cycling parameters were used: denaturation at $94^{\circ} \mathrm{C}$ for $5 \mathrm{~min}$, followed by 40 cycles of denaturation at $94^{\circ} \mathrm{C}$ for $30 \mathrm{sec}$, annealing at $42^{\circ} \mathrm{C}$ for $1 \mathrm{~min}$ and extension at $72^{\circ} \mathrm{C}$ for $1.5 \mathrm{~min}$, followed by one additional extension cycle at $72^{\circ} \mathrm{C}$ for $5 \mathrm{~min}$. The PCR products were electrophoresed on a $5 \%$ denaturing polyacrylamide sequencing gel and visualized using SYBR green. Differentially upregulated bands were recovered from dried gels and reamplified by PCR. The resulting cDNA products (879 bp cDNA fragment) were cloned into a TA vector according to the manufacturer's protocol (Invitrogen, San Diego, CA).

In situ hybridization. In situ hybridization was performed as described previously (Kiryu et al., 1995). Briefly, brains from decapitated animals were immediately frozen on dry ice, and sections $(20 \mu \mathrm{m})$ were cut on a cryostat with 2800 Feigocut E (Reichert-Jung, Vienna, Austria) and then thaw mounted onto 3-aminopropyltriethoxysilane-coated slides and stored at $-80^{\circ} \mathrm{C}$ until use. ${ }^{35} \mathrm{~S}$-labeled RNA probes were prepared by in vitro transcription of AIGP1 cDNA in the pGEM-T vector with SP6 or T7 RNA polymerase and $\alpha-\left[{ }^{35} \mathrm{~S}\right]$ UTP (DuPont NEN, Wilmington, DE).

Relative quantification of $m R N A$. The grain intensity of $\mathrm{x}$-ray films from autoradiograms was measured, and the area of autoradiographic grains in hypoglossal nuclei was quantified using image analysis software (MCID, Imaging Research, Ontario, Canada). Differences in grain intensity between the right (operated side) and left (contrateral side) hypoglossal nuclei from equivalent sections were then calculated. For statistical analyses, at least eight sections from five mice were studied, 
and the significance of these differences was determined using ANOVA (Kiryu-Seo et al., 2000).

Molecular cloning. Approximately $1.0 \times 10^{6}$ recombinant phage in a mouse brain library (Stratagene, La Jolla, CA) were screened by plaque hybridization using the $879 \mathrm{bp}$ cDNA fragment from NGS DD-PCR as a probe. This probe was labeled with $\left[\alpha-{ }^{32} \mathrm{P}\right] \mathrm{dCTP}$ using the Megaprime labeling system (Amersham Biosciences, Piscataway, NJ). Hybridization was performed at $42^{\circ} \mathrm{C}$ for $16 \mathrm{hr}$ in solution containing $50 \%$ formamide, $5 \times$ SSC $(0.75 \mathrm{M} \mathrm{NaCl}, 75 \mathrm{~mm}$ Na-citrate $), 5 \times$ Denhardt's solution $(0.1 \%$ BSA, $0.1 \%$ Ficoll $400,0.1 \%$ polyvinylpyrrolidone), $1 \%$ SDS, and 0.2 $\mathrm{mg} / \mathrm{ml}$ salmon testis DNA, washed twice at $65^{\circ} \mathrm{C}$ for $30 \mathrm{~min}$ in buffer containing $2 \times \mathrm{SSC}$ and $0.1 \% \mathrm{SDS}$, and washed again at $65^{\circ} \mathrm{C}$ for $30 \mathrm{~min}$ in buffer containing $0.2 \times$ SSC and $0.1 \%$ SDS. Independent positive clones were identified and sequenced by the dideoxynucleotide chain termination method with a Big Dye Deoxy Terminator cycle sequencing kit in an ABI 377 Prism automated DNA sequencer (Applied Biosystems, Foster City, CA).

Expression vectors. To construct a C-terminal Myc-tagged AIGP1 expression vector (pCIneo-AIGP1myc), PCR was performed with pBluescript (SK-) mouse AIGP1 (DDBJ accession no. AB029499) as a template and the following primers: $5^{\prime}$-GGCCTCGAGCCGCCATGGGGGCCGTCCTCG-3' and 5'-GCGGCCGCTCACAAGTCTTCTTCAGAAATAAGCTTTTGTTCGCTGAAGTCCCGACCTGTGA-3' . For constructing the N-terminal FLAG-tagged AIGP1 expression vector (pCIneo-FLAG-AIGP1), PCR was performed with pBluescript (SK-) AIGP1 template and the following primers: 5'-GGGGCTCGAGCCGCCATGGACTACAAGGACGACGATGACAAGATGGGGGCCGTCCTCGGCGT-3' and 5'-GGGGGCGGCCGCTCAGCTGAAGTCCCGACCTGT-3'. C-terminal Myc-tagged TPO1 expression vector (pCIneo-TPO1-myc) was constructed using PCR with pBluescript (SK-) mouse TPO1 (DDBJ accession no. AB029501) as a template and the following primers: 5'-GGCCTCGAGCCGCCATGTCTGCCCGGTGCTG-3' and 5'-GCGGCCGCTCACAAGTCTTCTTCAGAAATAAGCTTTTGTTCGACAGAGAACGCCTGGAGG-3'. To obtain mouse presenilin-1 cDNA, the entire open reading frame of the gene was amplified from the mouse brain cDNA library (Stratagene) by PCR with the primers 5'-GCTGCTCCAATGACAGAGAT-3' and 5'-GCTTGCTCTCTGTTTTTGTG-3'. The amplified cDNA fragment was inserted into pGEM-T vector using the TA cloning Kit (Promega) to produce pGEM-PS-1. To obtain N-terminal FLAG-tagged mouse presenilin-1 expression vector (pCIneo-NFLAGPS-1), PCR was performed with pGEM-PS-1 template and the primers 5'-GGGGCTCGAGCCGCCATGGACTACAAGGACGACGATGACAAGACAGAGATACGTGCACCTTTGT-3' and 5'-GGGGGCGGCCGCCTAGATATTAAACTGATGGAA-3'. Deletion mutant AIGP1 expression vectors were constructed by PCR using the following primers: 5'-GGGGCTCGAGCCGCCATGGACTACAAGGACGACGATGACAAGATGGGGGCCGTCCTCGGCGT-3' (upper primer for all mutants), 5'-GGGGGCGGCCGCTCAATCCTCTTCATCATTGGCTCC-3' (lower primer for pCI-neo FLAG AIGP16D1), 5'-GGGGGCGGCCGCTCATTTAGGGAGGATGGACACAAT-3' (lower primer for pCI-neo FLAG AIGP15D2), 5'-GGGGGCGGCCGCTCAGTGAGCCATGTCTACCAAGAG-3' (lower primer for pCI-neo FLAG AIGP14D3), and 5'GGGGGCGGCCGCTCATCTGGGATCTTTACTTGTTTT-3' (lower primer for pCI-neo FLAG AIGP13D4). The following PCR cycling parameters were used: denaturation at $95^{\circ} \mathrm{C}$ for $1 \mathrm{~min}, 25$ cycles with denaturation at $95^{\circ} \mathrm{C}$ for $1 \mathrm{~min}$, annealing at $46^{\circ} \mathrm{C}$ for $1 \mathrm{~min}$ and extension at $72^{\circ} \mathrm{C}$ for $1.5 \mathrm{~min}$, followed by one additional extension cycle at $72^{\circ} \mathrm{C}$ for 10 min. $P f u$ DNA polymerase was used for PCR and the amplified products were digested with XhoI and NotI and cloned between the XhoI and NotI sites of pCI-neo vector (Promega). All constructs were sequenced to confirm the DNA sequence. The EYFP vectors, pEYFP-mito, pEYFP-Golgi and $\mathrm{pEYFP}-\mathrm{ER}$, were purchased from Clontech (Palo Alto, CA), and the pSV2- $\beta$-gal vector was obtained from Promega.

Cell culture and transfection. Fetal C57BL/6J mouse embryos at 14-15 $\mathrm{d}$ of gestation were used for primary culture of embryonic cortical neurons (Nakagawa et al., 2000). The brain of each embryo was separated from overlying meninges, blood vessels, olfactory bulb, and hippocampus in HBSS. Dissected cortical tissue was mechanically dissociated using a $0.1 \mathrm{~mm}$ blade (Feather, Osaka, Japan) and treated with $0.25 \%$ trypsin and $0.1 \%$ DNase I (Sigma) in serum-free neurobasal MEM (Invitrogen). Enzymatic digestion was terminated by incubation with $10 \%$ heat-inactivated horse serum (HS) (Hyclone, Logan, UT), after which cells were mechanically disrupted by pipetting. After brief centrifugation, cells were suspended in neurobasal MEM containing B27 supplement (Invitrogen) and seeded on poly-D-lysine-coated chamber slides or poly-D-lysine-coated 24-well dishes at a concentration of $2 \times 10^{5}$ cells per well. Cortical neuron cultures were grown at $37^{\circ} \mathrm{C}$ in $5 \% \mathrm{CO}_{2}$. COS-7, human embryonic kidney (HEK) 293, and HeLa cells were grown in DMEM containing 10\% FBS (Hyclone), $100 \mathrm{U} / \mathrm{ml}$ penicillin, and $100 \mu \mathrm{g} / \mathrm{ml}$ streptomycin (Invitrogen), and PC-12 cells were grown in RPMI 1640 containing 10\% HS (Hyclone) and 5\% FBS (Hyclone). Neuro2a cells were grown in MEM containing 10\% FBS. Cells were transfected with Lipofectamine reagent (Invitrogen) following the manufacturer's instructions.

Antibody production. A polyclonal antibody against AIGP1 (ABEP56) was obtained by immunizing rabbits with the synthetic peptide EP56 (CEGGFQIKMVDTKAEKD; amino acid positions 71-87 in mouse AIGP1). Rabbits were immunized with keyhole limpet hemocyanincoupled peptide in complete adjuvant four times at 2 week intervals. The antiserum was affinity purified with the EP56-coupled peptide column using a SulfoLink kit (Pierce, Rockford, IL) according to the manufacturer's protocol.

Western blotting. Monolayer primary cultured cortical neurons, PC-12 cells, or transfected COS-7 cells were washed twice with PBS and lysed for $10 \mathrm{~min}$ on ice in solution containing $0.5 \%$ digitonin, $0.5 \mathrm{M} \mathrm{NaCl}, 50$ mM Tris-HCl, pH 7.5, 5 mm EDTA, 1 mM PMSF, $20 \mu \mathrm{M}$ antipain, $20 \mu \mathrm{M}$ leupeptin, and $20 \mu \mathrm{M}$ pepstatin and then sonicated for $1 \mathrm{~min}$ on ice using the Handy Sonic model UR-20P (power level 3-4; TOMY, Tokyo, Japan). Protein concentrations of lysates were determined using Bio-Rad protein assay kits (Bio-Rad, Hercules, CA). Lysates were boiled for 10 min, resolved by $4-20 \%$ gradient SDS-PAGE, and transferred to polyvinylidene difluoride membranes (Bio-Rad) with a semidry electroblotter (Bio-Rad). The membrane was blocked by incubation overnight at $4{ }^{\circ} \mathrm{C}$ in $3 \%$ nonfat milk/PBS containing $0.1 \%$ Tween 20 . Anti-AIGP1 polyclonal antibody ABEP56 (0.5-2 $\mu \mathrm{g} / \mathrm{ml})$, anti-Myc monoclonal 9E10 (1:500), or anti-FLAG M2 monoclonal antibody (1:1000) was used as a primary antibody in Western blotting. Either anti-rabbit IgG conjugated with horseradish peroxidase (Dako, Carpinteria, CA) or anti-mouse IgG conjugated with horseradish peroxidase (Dako) (1:2000) was used as secondary antibody. Immunoreactive bands were detected using the supersignal substrate system (Pierce) according to manufacturer's instructions.

Glycosidase treatment. For glycosidase treatment of AIGP1 protein, cell lysates were boiled at $100^{\circ} \mathrm{C}$ in the presence of $1 \%$ SDS after which $0.5 \%(\mathrm{w} / \mathrm{v})$ Nonidet P-40 was added, and the lysates were incubated at $37^{\circ} \mathrm{C}$ for $1 \mathrm{hr}$ with $5 \mathrm{U} / \mathrm{ml} \mathrm{N}$-glycosidase $\mathrm{F}$ (Roche, Indianapolis, IN).

Immunofluorescence microscopy. Monolayer primary cultured neurons, PC12 cells, transfected COS-7 cells, or Neuro2a cells were grown on slide-chamber dishes for immunofluorescence. All incubations and washes were performed at room temperature. Cells were fixed with $4 \%$ paraformaldehyde, washed three times with PBS, permeabilized with $0.2 \%$ Triton X-100/PBS for $4 \mathrm{~min}$, and finally washed three times with PBS. Fixed cells were incubated for $1 \mathrm{hr}$ with $3 \%$ goat serum (Nichirei, Tokyo, Japan) and washed with PBS. Cells were incubated with diluted primary polyclonal or monoclonal antibody (both were used for doublestaining). Next, these cells were incubated for $30 \mathrm{~min}$ with diluted secondary antibody conjugated to fluorescein and washed with PBS. Dilutions of primary antibodies were as follows: anti-Myc 9E10, 1:100; anti-FLAG M2, 1:2000; anti-Tau1, 1:500; anti-Map2, 1:500; anti-synapsin I, 1:500; anti-TGN46, 1:1000, and anti- $\beta$-galactosidase, 1:4000. All secondary antibodies were diluted 1:500. Immunofluorescence microscopy was performed with a Quantix cooled CCD camera system (Photometrics, Tucson, AZ), and the FLUOVIEW confocal microscope system (Olympus, Tokyo, Japan) was used for confocal microscopy.

The specificity of AIGP1 staining was confirmed as follows. (1) Staining with affinity-purified ABEP56 revealed Golgi complex-specific staining in COS-7 cells transfected with the AIGP1 expression construct, whereas no signal was observed in COS-7 cells transfected with a mock construct. (2) Affinity-purified ABEP56 was preincubated with 100 -fold excess EP56 or an unrelated peptide as a negative control. AIGP1 staining was abolished by preabsorption with EP56 antigen. However, incubation with the control peptide had no effect on staining. (3) No signal was observed when cells or tissue sections were stained with preimmune sera (data not shown). (4) Staining with affinity-purified anti-TPO1 (a member of the AIGP1 protein family) revealed no Golgi complex-specific staining in cortical neurons (data not shown).

$S Y B R$ green-based real-time quantitative RT-PCR. SYBR green-based real-time quantitative RT-PCR was performed as described (Wong et al., 2000; Aoki et al., 2002). Total RNA was prepared from $2 \times 10^{5}$ cortical 
neurons cultured for $12 \mathrm{hr}$ under stress conditions (B27 supplement deprivation, $10 \mu \mathrm{g} / \mathrm{ml}$ tunicamycin, $10 \mu \mathrm{g} / \mathrm{ml}$ brefeldin A, $0.2 \mu \mathrm{M}$ staurosporin, $250 \mu \mathrm{M} \mathrm{H}_{2} \mathrm{O}_{2}$, and $1 \mu \mathrm{M}$ cytochalasin D). Total RNA $(2 \mu \mathrm{g})$ was treated with DNase I and converted to cDNA using Superscript reverse transcriptase (Invitrogen) and random hexamer primers. SYBR greenbased real-time RT-PCR was performed in $50 \mu \mathrm{l}$ reactions (Applied Biosystems 7700 Sequence Detection System). The following primer pairs were used: 5'-GAGCATCCGTACCTCCAACAA-3' (upper) and 5'-GTCACTTCTGCCATTCCCATC-3' (lower) for amplification of AIGP1, and 5'-ACGGCCAGGTCATCACTATTG-3' (upper) and 5'ATGCCACAGGATTCCATACCC-3' (lower) for amplification of $\beta$-actin. Control experiments (determinations of melting temperature and DNA sequences of PCR products) established that the signal for each amplicon was derived from cDNA and not from primer-dimers. The quantitative RT-PCR method (User Bulletin \#2, Applied Biosystems) was modified to establish an expression level index for mRNA (Aoki et al., 2002), and the SYBR green signal for $\beta$-actin amplicon was used as a calibrator. Amplification efficiency was determined in a control PCR experiment using serial cDNA diluents as templates.

Terminal deoxynucleotidyl transferase-mediated fluorescein UTP nick end-labeling. To detect DNA fragmentation in cultured cells, the modified terminal deoxynucleotidyl transferase (TdT)-mediated fluorescein UTP nick end-labeling (fluorescein TUNEL) procedure was performed with an Apoptosis Detection System Fluorescein kit (Promega) using protocols provided by the manufacturer. Briefly, cultured cells grown on slides were fixed in $4 \%$ formaldehyde in PBS and then washed with PBS and permeabilized in $0.2 \%$ Triton X-100 in PBS for 5 min. DNA strand breaks of cell nuclei were labeled with fluorescein-12-dUTP using TdT. After fluorescein TUNEL staining, transfected cells were further stained with anti-Myc 9E10, anti-FLAG M2, or anti- $\beta$-gal. For statistical analyses of cell death rates, at least four independent wells were studied.

\section{RESULTS}

\section{Identification of an axotomy-induced gene encoding an $\mathrm{N}$-linked glycosylated protein}

$\mathrm{N}$-linked glycosylation of proteins in eukaryotic cells is initiated within the endoplasmic reticulum where a core oligosaccharide (14-mer) composed of $N$-acetylglucosamine, mannose, and glucose is transferred to the side chain of the asparagine within the NGS sequence Asn-X-Ser/Thr (Kornfeld and Kornfeld, 1985; Abeijon and Hirschberg, 1992; Hart, 1992) of the protein. We established a novel NGS DD-PCR method for screening differentially expressed genes encoding $\mathrm{N}$-linked glycosylated proteins using a degenerate oligonucleotide $[\mathrm{AA}(\mathrm{C} / \mathrm{T})-\mathrm{NNN}-(\mathrm{A} / \mathrm{T})(\mathrm{G} /$ $\mathrm{C}) \mathrm{N}$ ] containing the Asn-X-Ser/Thr consensus sequence (Fig. $1 A$ ). Using a hemihypoglossal nerve transection model in adult mice, the hypoglossal nuclei of injured and contralateral (control) sides were collected from 90 mice at $7 \mathrm{~d}$ after operation and subjected to analysis by the novel NGS DD-PCR method. The procedure yielded many PCR products (Fig. $1 B$ ), the sequences of which were determined to identify glycoprotein-encoding genes that were selectively amplified. Nearly all of the sequences represented novel, uncharacterized genes. This result was expected given that the number of characterized glycoproteins is likely very small compared with those that remain uncharacterized. Among the selectively amplified PCR products, an increased level of an 879 bp product was detected on the injured side (Fig. 1B, arrowhead). A histological survey using this $879 \mathrm{bp}$ cDNA fragment as a probe demonstrated increased mRNA expression in hypoglossal nuclei from the injured side on day 7 after axotomy (Fig. 1C, arrow). Furthermore, Nissl staining revealed specific localization of this mRNA to neurons (Fig. 1C, bottom). The intensity of the signals markedly increased after $3 \mathrm{~d}$, stayed at plateau for 1 week, and then gradually decreased to control levels over the next 2 weeks (Fig. $1 D$ ). We detected other upregulated bands in NGS DD-PCR (Fig. 1B), but induction of those transcripts was not detected during subsequent in situ hybridization analysis (data not shown).

To isolate full-length cDNA corresponding to the 879 bp PCR product, we screened $\sim 1 \times 10^{6}$ recombinant phage from a mouse brain cDNA library. Several positive clones were identified. Fulllength cDNA contained an 879 bp sequence identical to that obtained from DD-PCR cloning. The $2.2 \mathrm{~kb}$ full-length nucleotide sequence (DDBJ accession no. AB029499) comprises a 1416 bp open reading frame encoding 472 amino acids. The translation initiation Kozak sequence includes a methionine codon (ACCATGG), and the $3^{\prime}$ noncoding region contains an AU-rich sequence implicated in mRNA instability (Sachs, 1993). Two NGSs (Asn-Ser-Thr) were identified at amino acid positions 34-36 and 315-317, and the latter corresponds to the NGS primer binding site of the cDNA sequence. Swiss/Prot, GenBank, and European Molecular Biology Laboratory database searches revealed that the amino acid sequence is either identical or highly homologous to mouse MUSTETU (100\%; GenBank accession number L29441), mouse TMS-1 (99.8\%; AF181684), and human Diff33 (68.6\%; U49188) and displays a moderate level of homology (30-60\%) to rat TPO1 (L20319), mouse TMS-2 (AF181685), Caenorhabditis elegans tms-1, Drosophila melanogaster (AF181686), and Saccharomyces cerevisiae TMS1 (Z47746). Mouse MUSTETU, human Diff33, TPO1, and TMS genes were characterized in previous studies (Lebel and Mes-Masson 1994; Krueger et al., 1997; Grossman et al., 2000), although no data on the native proteins or their biological functions were presented. We conclude that the protein that we identified represents a novel axotomy-induced factor. The protein was designated axotomy-induced glycosylated/Golgicomplex protein 1 on the basis of its physical and functional characteristics (see below).

\section{AIGP1 is an $\mathbf{N}$-linked glycosylated membrane protein}

Analysis of AIGP1 using hydropathy plots indicated the existence of multiple clusters of 16-23 hydrophobic amino acids, in agreement with data on related membrane proteins (Krueger et al., 1997; Grossman et al., 2000), suggesting that AIGP1 is a transmembrane protein. To confirm this hypothesis, we used two programs that adopt different algorithms for the prediction of transmembrane regions, specifically, SOSUI (http://sosui.proteome.bio. tuat.ac.jp/sosuimenu0.html) and TMpred (http://www.ch.embnet. org/software/TMPRED_form.html). These analyses predicted that AIGP1 contains $11^{-}$putative transmembrane domains. Although a number of studies on members of this gene family (including the AIGP1 gene) have been reported (Lebel and Mes-Masson 1994; Krueger et al., 1997; Grossman et al., 2000), the corresponding native proteins have never been identified either in vivo or in vitro. The primary limitation in such studies has been the inability to produce antibodies against proteins of this family, attributable presumably to their low antigenicity and high hydrophobicity. In fact, previous efforts to produce antibodies against TPO1, a member of this protein family that is specifically expressed in developing oligodendrocytes, were unsuccessful (Krueger et al., 1997). In our attempts to produce specific antibodies against AIGP1 using antigenic peptides, only peptide EP56 showed promise as a candidate antigen. Using this antibody, Western blots of cell lysates from COS-7 cells transfected with an AIGP1 expression construct (Fig. 1E, lanes 3, 4) revealed a single band of $\sim 70 \mathrm{kDa}$. Consistent with these results, Western blots of lysates from PC-12 cells (Fig. 1E, lanes 6, 7) and primary cortical neurons (Fig. $2 F$ ) displayed a band of similar size. The theoretically molecular mass of AIGP1 is $52.6 \mathrm{kDa}$, which differs signif- 

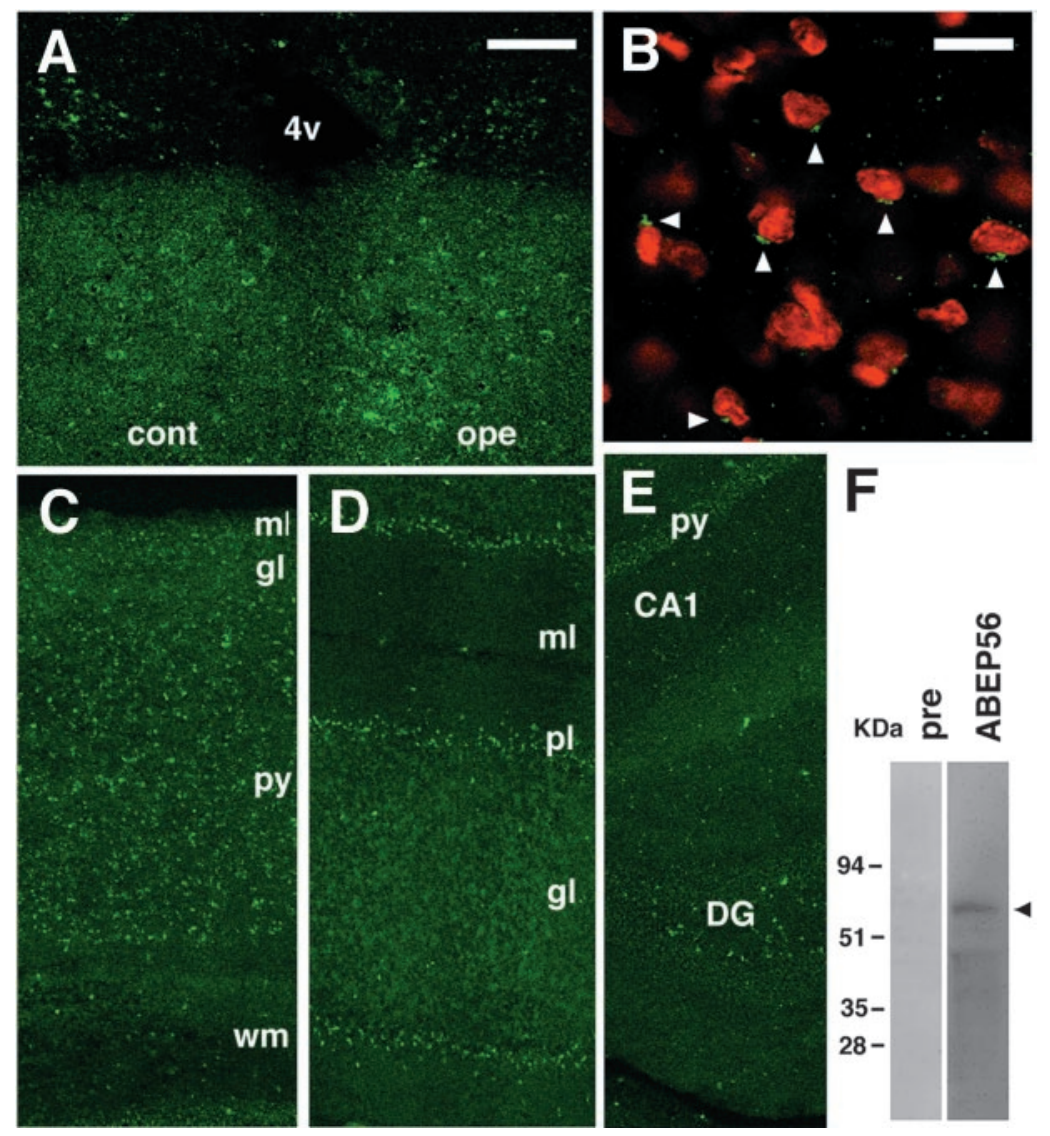

Figure 2. Localization of AIGP1 immunoreactivity in the mouse brain. A, Expression of AIGP1 (green) in the mouse brain examined by fluorescent immunohistochemistry with polyclonal antibody ABEP56. A section $(25 \mu \mathrm{m})$ was obtained from a unilateral hypoglossal nerve-transected mouse $7 \mathrm{~d}$ after surgery. $B$, Staining with ABEP56 and propidium iodide (red) revealed AIGP1 localization (green) as a dot-like area adjacent to the nucleus. $C-E$, Tissue localization of AIGP1 in the cortex $(C)$, cerebellum $(D)$, and hippocampus $(E)$. Coronal sections were stained with ABEP56 and Alexa Flour 488labeled secondary antibody (green). Confocal images are presented. $F$, Mouse cortical neurons were lysed, and total protein was subjected to Western blotting with preimmune (pre) or ABEP56, respectively. 4v, Fourth ventricular; cont, control side; $o p$, operated side; $D G$, dentate gyrus; $g l$, granule cell layer; $p l$, Purkinje cell layer; $m l$, molecular cell layer; $p y$, pyramidal cell layer. Scale bars: $A, C, D, E, 300 \mu \mathrm{m} ; B, 15 \mu \mathrm{m}$. icantly from its apparent size. This discrepancy may be caused by glycosylation at Asn 34 and Asn 315 of AIGP1. To examine whether AIGP1 is an N-linked glycosylated protein, cell lysates were treated with $N$-glycosidase F and examined using Western blots. AIGP1 exhibited a mobility shift in $N$-glycosidase $\mathrm{F}(+)$ lysates (Fig. $1 E$, lanes 5,8 ) in contrast to $N$-glycosidase $\mathrm{F}(-$ ) lysates in the same buffer (Fig. $1 E$, lanes 4,7 ). The apparent molecular mass of the deglycosylated protein was $\sim 50 \mathrm{kDa}$, in good agreement with the theoretical molecular mass. Given that AIGP1 contains two NGSs, these results strongly suggest that AIGP1 is an N-linked glycosylated protein.

\section{AIGP1 is specifically localized to the Golgi complex in neurons}

In situ hybridization data in Figure $1 C$ demonstrate AIGP1 mRNA localization in motoneurons of hypoglossal nuclei. To elucidate the distribution of AIGP1 in the mouse brain, immunohistochemical studies were performed using antibody ABEP56 that recognizes mouse and rat AIGP1 (Fig. 2) but not other family members such as mouse TMS-2 or TPO1 (data not shown). AIGP1 expression was detected in the cortex, hippocampus, cerebellum, and hypoglossal nucleus in the mouse brain (Fig. $2 A, C, D)$. AIGP1 immunoreactivity in the hypoglossal nucleus was specifically elevated after axotomy (Fig. $2 A$, right side). Most AIGP1-positive cells in the cortex, hippocampus, and cerebellum were neurons, and most immunostaining patterns were consistent with results from in situ hybridization studies (Figs. 1C, 2D) (Grossman et al., 2000). Furthermore, AIGP1 staining was predominantly localized to perinuclear membranes as small dot-like structures (Fig. 2B). To identify the subcellular localization of AIGP1 in neurons, we performed immunofluorescence staining with cultured cortical neurons. Axons and dendrites of culture cells used in this study were distinguished by staining with antibodies to Tau-1 (marker for axons) and Map-2 (marker for dendrites) (data not shown). Synaptic contacts were established 12-13 d after plating, as verified by staining with anti-synapsin I (Fig. 3E) and anti-GluR2/3 (a postsynaptic marker; data not shown). AIGP1 staining was detected in cortical neurons from initial cultivation onward (Fig. 3B). After plating for $8 \mathrm{hr}$, AIGP1 was localized near the nucleus as diff use vesicle structures in the cytoplasm, whereas no specific signal was observed with the preabsorbed antibody sample (Fig. $3 A$ ). At 1 and $2 \mathrm{~d}$ after plating, the AIGP1 signal was concentrated adjacent to the nucleus as a dot-like (or tube-like) structure that resembled the Golgi complex (Fig. 3C,D). In mature neurons with synapsin I-positive synapses, AIGP1 staining was also observed in Golgi-like structures (Fig. $3 E$ ). A double-staining experiment with $\mathrm{PC} 12$ cells was performed to confirm that AIGP1 is present in the Golgi complex. Anti-TGN-46 was used as a trans-Golgi marker, because localization of this protein to the Golgi apparatus has been confirmed at the ultrastructural level (Prescott et al., 1997). AIGP1 colocalized with TGN-46 (Fig. 3G-I), whereas the AIGP1 staining pattern in cortical neurons differed from that of membrin, a marker for ER and cis-Golgi (Hay et al., 1997) (Fig. 3F). The Golgi localization of AIGP1 was further confirmed by immunostaining in COS-7 cells after cotransfection of AIGP1 with either pEYFP-ER, pEYFP-Golgi, or pEYFP-mito, constructs that label the ER, Golgi, and mitochondria, respectively. AIGP1 clearly colocalized with the pEYFP-Golgi marker (Fig. $4 D-F$ ) but not with that of pEYFP-ER or pEYFP-mito (Fig. $4 A-C, G-I$ ). This result confirmed that AIGP1 localizes specifically to the Golgi complex and 

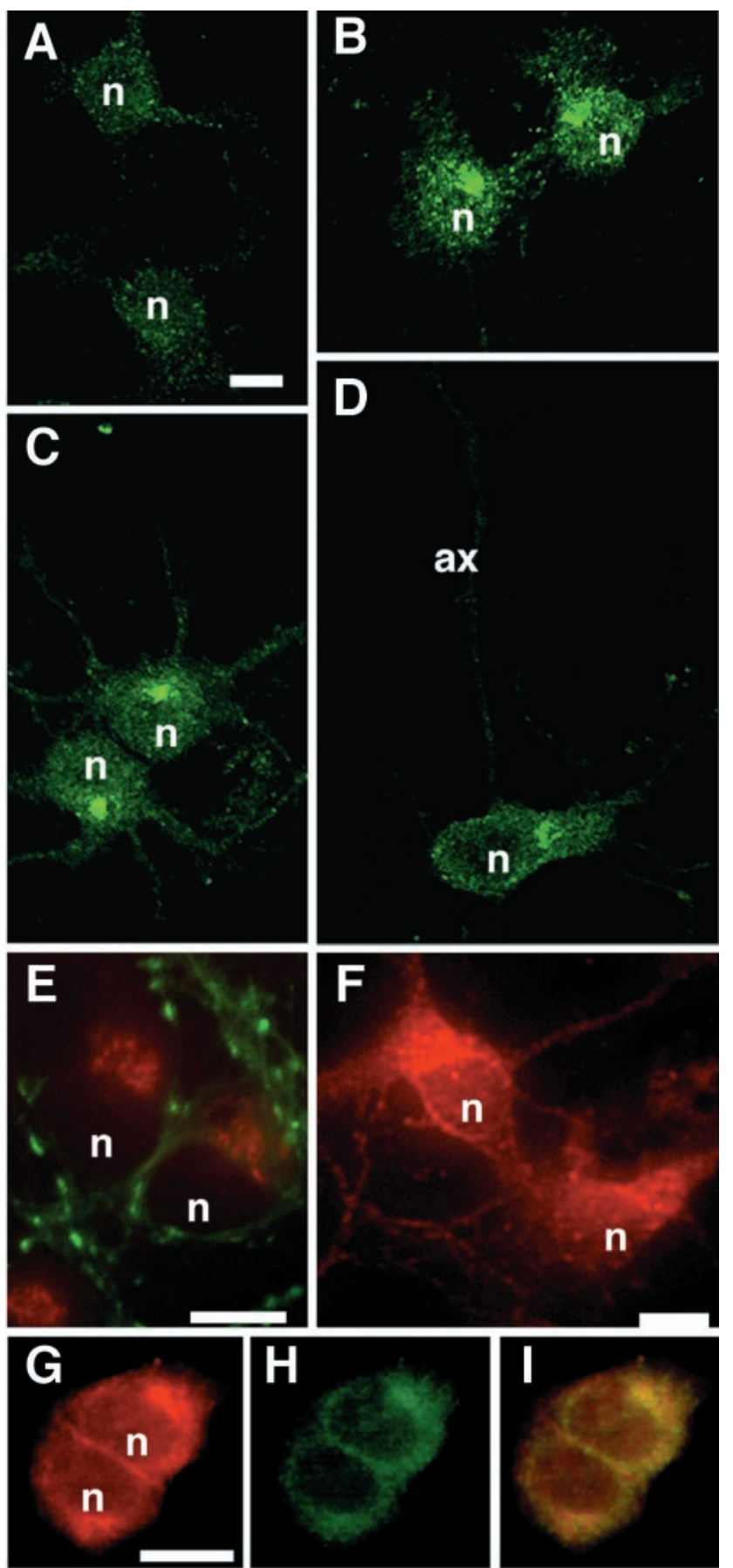

Figure 3. Localization of AIGP1 immunostaining in mouse cultured cortical neurons and $\mathrm{PC} 12$ cells. Primary cultured cortical neurons were fixed at $8 \mathrm{hr}(A, B), 24 \mathrm{hr}(C)$, and $48 \mathrm{hr}(D)$ after plating and stained with polyclonal antibody ABEP56 and Alexa Flour 488-labeled secondary antibody ( green). Specificity of staining was verified by preabsorption of ABEP56 with 100-fold excess peptide EP56 $(A)$ or negative control peptide $(B)$. E, Primary cultured cortical neurons were fixed $13 \mathrm{~d}$ after plating and coimmunostained with ABEP56 and Alexa Flour 594 (red) and monoclonal anti-synapsin-I and Alexa Flour 488 ( green). F, Primary cultured cortical neurons were fixed $48 \mathrm{hr}$ after plating and immunostained with polyclonal anti-membrin and Alexa Flour 594 (red). $G-I$, PC12 cells were coimmunostained with ABEP56 (red) $(G)$ and monoclonal anti-TGN46 (green) $(H) . I$, Merged image of $G$ and $H$. Both Alexa Flour 488-labeled anti-rabbit IgG and Alexa Flour 594-labeled antimouse IgG were used as secondary antibodies for double-staining $(G-I)$. $A-D$ and $E-I$ are confocal and cooled CCD images, respectively. Scale bars: $A-D, 10 \mu \mathrm{m} ; E, F, 15 \mu \mathrm{m} ; G-I, 10 \mu \mathrm{m}$.
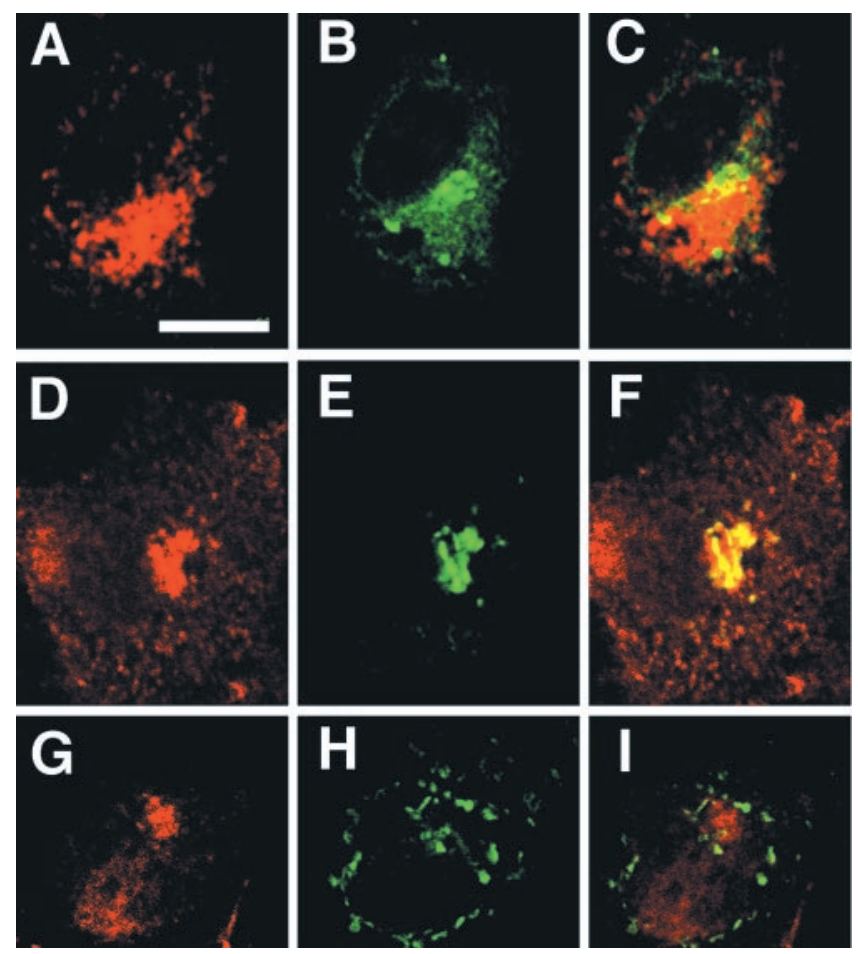

Figure 4. AIGP1 immunostaining is specifically localized to the Golgi in transfected COS-7 cells. COS-7 cells were cotransfected with $\mathrm{N}$-terminal FLAG-tagged AIGP1 and pEYFP constructs: pEYFP-ER $(A-C)$, pEYFP-Golgi $(D-F)$, or pEYFP-mito $(G-I)$. Cells were fixed $24 \mathrm{hr}$ after transfection and stained with anti-FLAG M2. Confocal images of FLAG immunostaining with Alexa Fluor 594-labeled anti-mouse $\operatorname{IgG}(A, D, G)$ and EYFP fluorescence $(B, E, H) . C, F$, and $I$ represent merged images. Similar results were obtained in four independent experiments. Scale bar, $10 \mu \mathrm{m}$.

not to the endoplasmic reticulum or mitochondria. Additional cotransfection experiments with these pEYFP expression constructs using HeLa and HEK293 cells also showed that AIGP1 predominantly localizes to the Golgi (data not shown).

\section{AIGP1 expression is specifically induced by ER-Golgi stress in neurons}

AIGP1 is localized to the Golgi complex, and its expression is specifically induced in response to axotomy. To clarify the molecular basis of axotomy-induced AIGP1 expression, we performed SYBR green-based real-time RT-PCR and analyzed gene expression in cultured neurons under several stress conditions, including oxidative stress, ER-Golgi stress, trophic factor deprivation, cytoskeletal disruption, and staurosporine treatment. Control experiments established optimal stress conditions that induced $30-40 \%$ death of cortical neurons after $12 \mathrm{hr}$ (data not shown). Among several stress conditions, only the ER-Golgi stressors brefeldin A and tunicamycin markedly activated AIGP1 expression (Fig. 5A,B) (tunicamycin: $4.03 \pm 0.81$-fold, $p=0.003$; brefeldin A: $5.92 \pm 0.62$-fold, $p=0.0002$ ). AIGP1 expression was activated to a much lesser extent by three other stressors, including $\mathrm{B} 27(-)$, STS, and $\mathrm{H}_{2} \mathrm{O}_{2}$, but was not activated by cytochalasin $\mathrm{D}($ Fig. $5 A, B)$.

\section{Frequency of cell death is modulated by AIGP1} expression in COS-7 cells

The $S$. cerevisiae gene $t m s-1$ is the only gene encoding an ortholog of AIGP1 in yeast. Loss-of-function experiments have been per- 


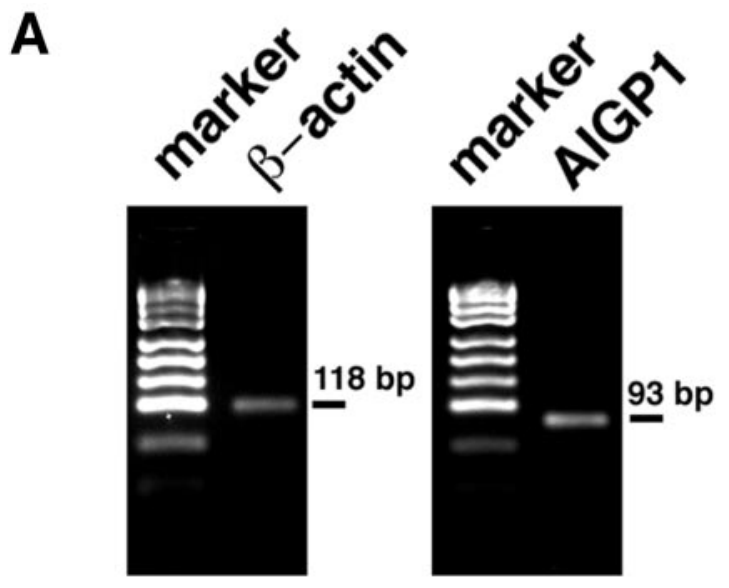

B

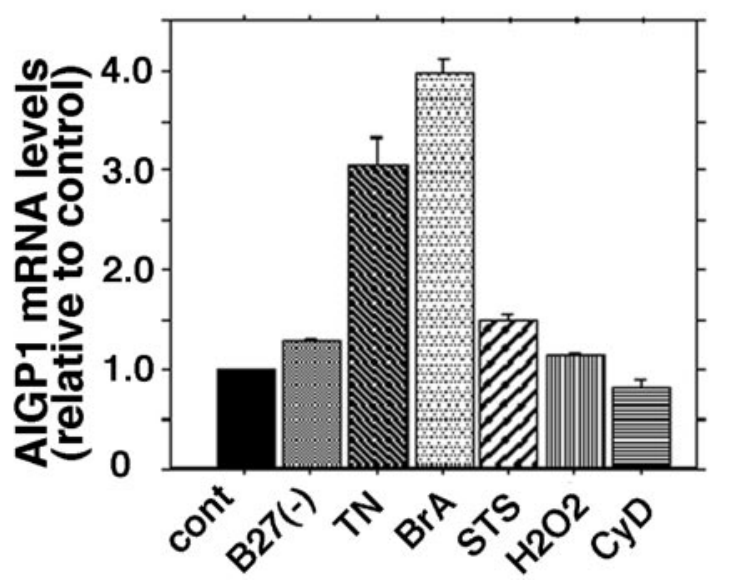

Figure 5. ER-Golgi stress specifically induced AIGP1 expression in cultured cortical neurons. $A$, After 40 cycles of PCR with primers that recognize either $\beta$-actin or AIGP1 cDNA sequences, reaction products $(\beta$-actin $=118 \mathrm{bp} ; A I G P 1=93 \mathrm{bp})$ were resolved by $2 \%$ agarose gel electrophoresis. $B$, Three days after plating, cortical neurons were cultured for $12 \mathrm{hr}$ under the following stress conditions: B27 supplement deprivation $[B 27(-)], 10 \mu \mathrm{g} / \mathrm{ml}$ tunicamycin $(T N), 10 \mu \mathrm{g} / \mathrm{ml}$ brefeldin A (BrA), $0.2 \mu \mathrm{M}$ staurosporin (STS), $250 \mu \mathrm{M} \mathrm{H}_{2} \mathrm{O}_{2}$ (H202), or $1 \mu \mathrm{M}$ cytochalasin $\mathrm{D}(C y D)$. Each cDNA was prepared from random hexamer primers and total RNA from stress-treated cells. Real-time RT-PCR assays of AIGP1 mRNA expression were performed with SYBR green and ABI7700 sequence detection system. $\beta$-actin was used as an internal control. Similar results were obtained in three separate experiments using independent cortical neuron cultures. Error bars represent the SD calculated from quadruplicate samples at a minimum (from culture wells). ${ }^{* *} p<0.01$.

formed on $t m s-1$ via disruption by homologous recombination (Grossman et al., 2000). tms-1 null mutants were examined with regard to the effects of stress conditions, including temperature, osmotic stress, toxic chemicals, and metal ions; however, no apparent phenotype was observed. Thus, there may be a redundant metabolic pathway or gene, or both, that compensates for the loss of $t m s$ - 1 function in yeast. In our current gain-of-function experiments, AIGP1 constructs were transfected and overexpressed in COS-7 cells. As expected, exogenously expressed AIGP1 (visualized as a single band at $\sim 70 \mathrm{kDa}$ in COS-7 cells) (Fig. $1 E$ ) localized specifically to the Golgi (Fig. 4D-F). AIGP1 overexpression induced cell death as demonstrated by fluorescein
A
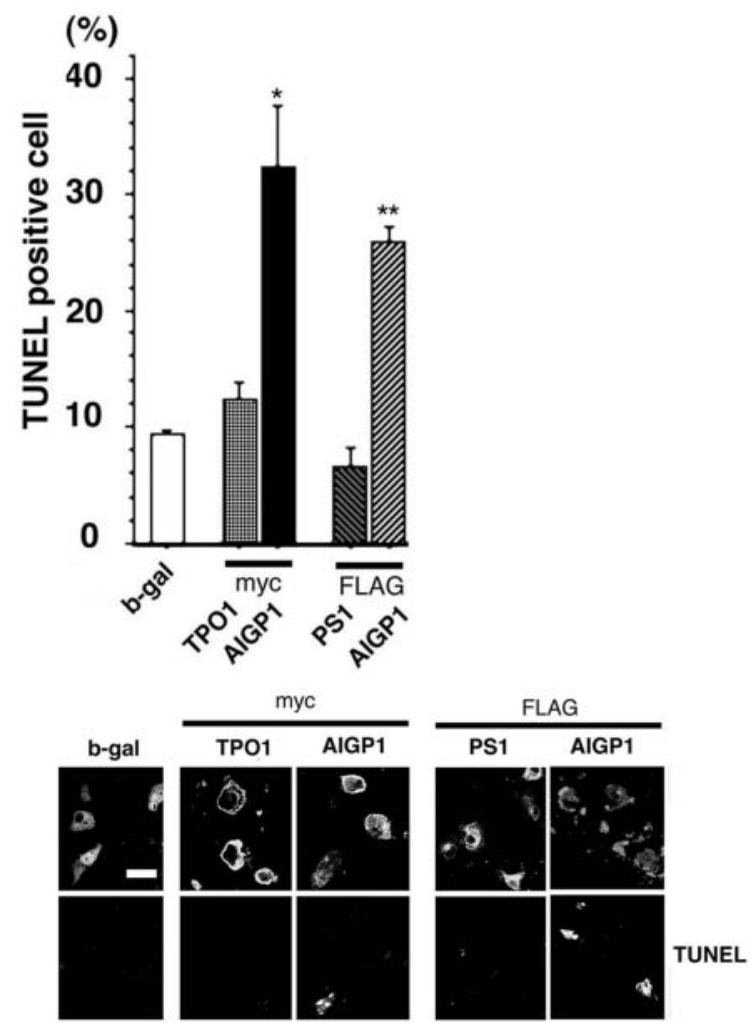

B

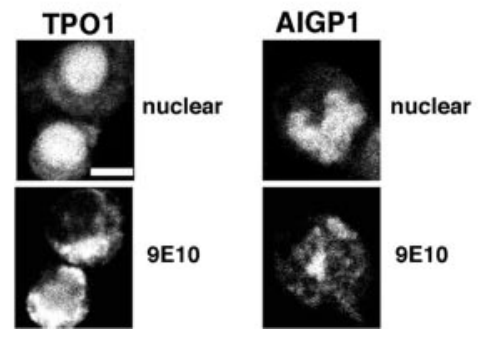

Figure 6. AIGP1 expression increases the frequency of cell death. $A$, COS-7 cells were transfected with constructs encoding $\beta$-galactosidase (b-gal), TPO1-myc, AIGP1-myc, N-FLAG-presenilin-1 (PS1), or N-FLAG-AIGP1. At $48 \mathrm{hr}$ after transfection, cells were fixed and stained with anti- $\beta$ gal $(A$, bottom; $b$-gal $)$, anti-myc 9E10 (A, bottom; TPO myc and $A I G P 1$ myc), or anti-FLAG M2 (A, bottom; FLAG PS1 and FLAG $A I G P 1)$. Cell death was determined by fluorescein TUNEL assay $(A$, bottom; TUNEL). Confocal images of immunostaining and the fluorescein TUNEL stains are presented $(A$, bottom $)$. The frequency of cell death (the number of fluorescein TUNEL-positive cells per $\beta$-gal, 9E10-, or FLAG-positive cells) was counted and presented as mean percentages $(A$, top $)$. Error bars represent SD calculated from quadruplicate samples. ${ }^{*} p<0.05 ;{ }^{*} p<0.01$. Scale bar, $20 \mu \mathrm{m}$. B, Nuclear crumpling of a Neuro2a cell transfected with an AIGP1 expression construct. Neuro2a cells were transfected with constructs encoding TPO1-myc or AIGP1myc. At $72 \mathrm{hr}$ after transfection, cells were fixed and stained with CYTO green (nuclear stain; top) and anti-myc 9E10 (bottom). Scale bar, $10 \mu \mathrm{m}$.

TUNEL assays in COS-7 cells transfected with AIGP1 [a $\beta$-galactosidase ( $\beta$-gal) construct served as a negative control]. At $48 \mathrm{hr}$ after transfection, cell death of COS-7 cells expressing C-terminal Myc-tagged or N-terminal FLAG-tagged AIGP1 was approximately threefold higher than that measured in cells expressing $\beta$-galactosidase (Fig. $6 A$ ) (AIGP1-myc, $32.3 \pm 5.3 \%$; FLAG-AIGP1, $25.9 \pm 1.3 \% ; \beta$-gal, $9.3 \pm 0.3 \%$; AIGP1-myc vs $\beta$-gal, $p=0.013$; FLAG-AIGP1 vs $\beta$-gal, $p=0.003)$. These 


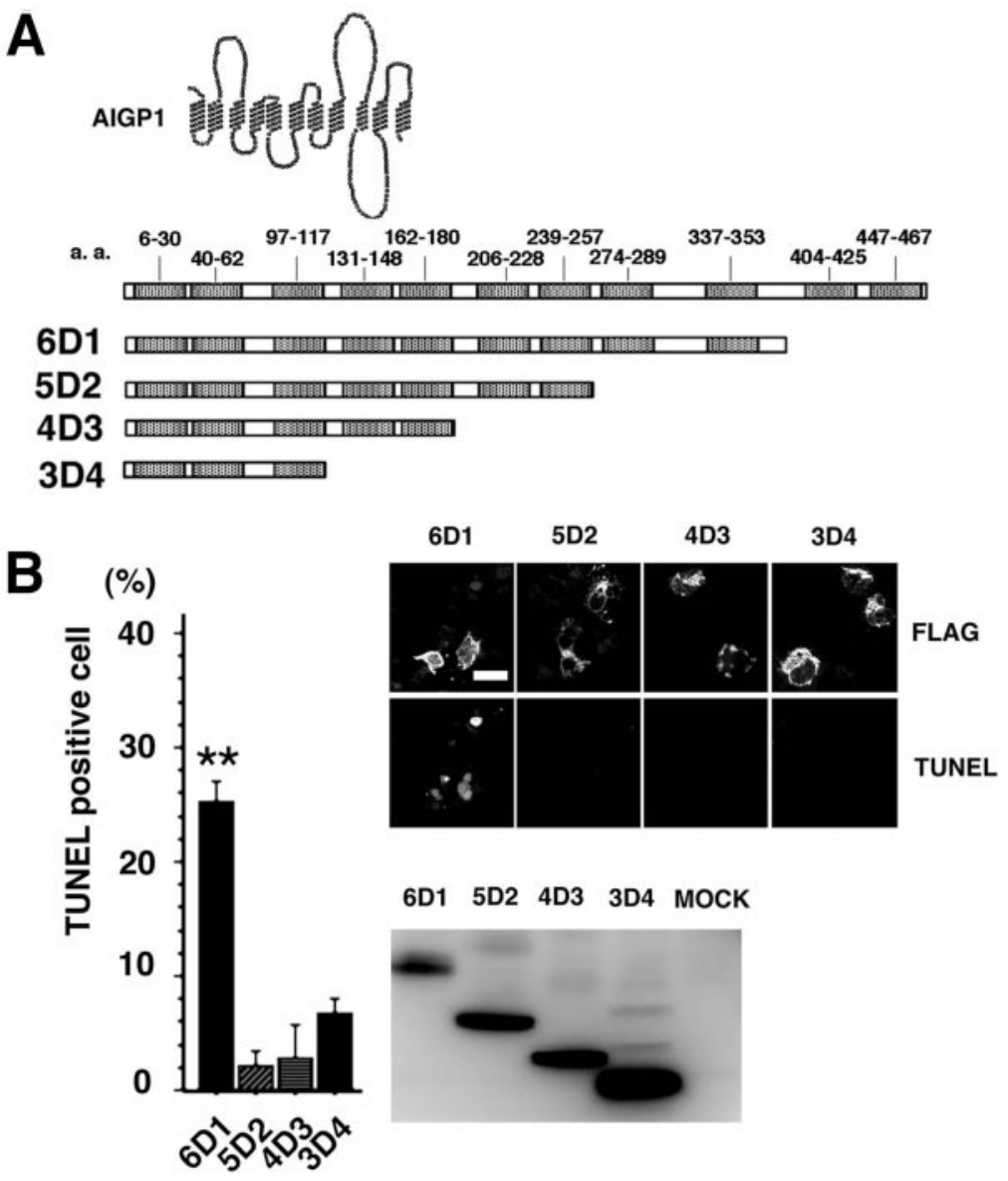

Figure 7. C-terminal deletion mutants of AIGP1 and induction of cell death. $A$, Schematic representation of AIGP1 structure and C-terminal deletion mutants. Locations of amino acid residues are indicated by numbers, and transmembrane domains are shown as gray boxes (Grossman et al., 2000). B, Loss of AIGP1 activity after deletion of the region containing the eighth and ninth helices and loops. COS-7 cells were transfected with a series of deletion mutants, fixed $48 \mathrm{hr}$ after transfection, and stained with anti-FLAG M2 antibody $(B$, right, top $)$. Cell death was analyzed by the fluorescein TUNEL method ( $B$, right, middle). Confocal images of FLAG immunostaining with Alexa Flour 594-labeled anti-mouse IgG and fluorescein TUNEL stains are presented ( $B$, right, top and middle). The frequency of cell death (TUNEL-positive cells per FLAG-positive cells) was counted and is presented as mean percentages $(B$, left $t$. Expression levels of mutant constructs were analyzed by Western blots with anti-FLAG M2 (8 $\mu$ g protein per lane) $(B$, right, bottom). Error bars represent SD calculated from at least four different samples. ${ }^{* *} p<0.01$. Scale bar, $20 \mu \mathrm{m}$.

differences were not evident $24 \mathrm{hr}$ after transfection (data not shown). In addition, COS-7 cells transfected with AIGP1 expression constructs displayed characteristic morphological changes, fragmentation of the cell body, and nuclear and cytoplasmic condensation (Fig. 6A). Furthermore, cell death and nuclear crumpling were also observed in a mouse neuronal cell (Neuro2a cell) transfected with AIGP1 expression constructs (Fig. 6B).

We transfected COS-7 cells with a construct for C-terminal Myc-tagged TPO1, an AIGP1 family member containing 11 transmembrane helices (Krueger et al., 1997), or N-terminal FLAGtagged presenilin-1, a multimeric transmembrane protein associated with Alzheimer's disease (Doan et al., 1996), as negative controls for N-terminal FLAG-tagged or C-terminal Myc-tagged multimeric transmembrane proteins. These membrane protein constructs did not induce cell death compared with the $\beta$-gal construct [TPO1-myc, $12.3 \pm 1.5 \%$ (no significant difference vs $\beta$-gal), FLAGPS1, $6.6 \pm 1.6 \%$ (no significant difference vs $\beta$-gal)], indicating the specificity of AIGP1 action (Fig. 6A). Expression of these negative control proteins was equivalent to that of AIGP1 and was confirmed both by Western blotting (data not shown) and by immunohistochemistry (Fig. 6A).

To further confirm the specific effect of AIGP1, AIGP1 deletion mutants were used. AIGP1 comprises 11 transmembrane helices and 10 loop structures. The roles of these structures have not been determined, although the eighth and ninth loops constitute the largest structures in this protein (Fig. 7A). Serial C-terminal deletion mutants of the AIGP1 were constructed. Analysis of the activity of these deletion mutants (Fig. $7 A$ ) revealed that the construct containing the eighth and ninth trans- membrane helices and loops (6D1) displayed significant activity [(Fig. $7 B$ ) $6 D 1,25.2 \pm 3.3 \%$ vs 5D2, $2.9 \pm 4.9 \% ; p=0.001$; (Fig. 6A) FLAGAIGP1, $25.9 \pm 1.3 \%$; no significant difference vs 6D1]. Mutant 5D2 is the longest deletion mutant that lacked significant activity, indicating that the $\mathrm{C}$ terminus, including the two transmembrane helices and loops, is required for AIGP1 function. The levels of expression and membrane localization of the mutant constructs that lacked activity did not differ from 6D1 (Fig. 7B), indicating that the loss of activity was probably caused by the absence of the effector sequence rather than by decreased protein expression levels or an altered localization.

\section{DISCUSSION}

We developed a novel method that enables the identification of genes encoding $\mathrm{N}$-linked glycosylated proteins whose expression levels may change with environmental conditions. This innovative procedure led to the discovery of an N-linked glycosylated protein AIGP-1, the expression of which is upregulated in response to both ER-Golgi stress in vitro and axotomy in vivo. We demonstrated that AIGP1 associates with the Golgi complex and may be involved in ER-Golgi stress-induced cell death after nerve injury.

AIGP1 is an axotomy-induced molecule in neurons. Experiments with cultured cortical neurons showed marked induction of AIGP1 gene expression by the ER-Golgi stressors tunicamycin (a specific inhibitor of N-glycosylation in the ER) and brefeldin A (an inhibitor of ER-Golgi transport). These drugs are effective inducers of ER-Golgi stress, as verified by their specific upregulation of numerous ER-stress response genes (Easton et al., 2000; 
Nakagawa et al., 2000; Lee, 2001). Our results suggest that axotomy induces ER-Golgi stress, thereby inducing AIGP1 expression in injured motor neurons.

To date, the biological functions of members of the AIGP1 protein family remain unknown, attributable primarily to difficulties in producing antibodies against these proteins (Lebel and Mes-Masson 1994; Krueger et al., 1997; Grossman et al., 2000). TMS genes are members of the AIGP1 family, and previous experiments involving enhanced green fluorescent protein chimeras of these genes showed that TMS proteins localize on the cell surface in HEK293 cells (Grossman et al., 2000). However, an AIGP1-specific antibody showed Golgi immunoreactivity only in neurons and failed to detect AIGP1 either on the cell surface or in synapses (Figs. 2B, 3E). Although AIGP1 localization may vary in different cell types and under different conditions (e.g., depending on cell-cell interactions and adhesion), it is clear that in neurons AIGP1 is localized to the Golgi, indicating that it most likely represents a resident Golgi membrane protein.

Resident proteins of the Golgi are primarily localized via two different mechanisms, namely the ER-retrieval mechanisms based on specific amino acid motifs [e.g., C-terminal KDEL (Munro and Pelham, 1987) and KKXX (Letourneur et al., 1994)] or by retention (Munro, 1995). One retention mechanism involves lipid-based sorting, which is determined by the length of transmembrane helices in integral membrane proteins. Proteins having a transmembrane helix shortened to 17 amino acids accumulate in the Golgi complex (Munro, 1995). Although no conventional ER-retrieval signals are evident in the AIGP1 amino acid sequence, the eighth and ninth transmembrane helices of the protein contain 16 and 17 amino acids, respectively (Grossman et al., 2000), thereby reinforcing the possibility that these helices represent potential lipid-based retention signals.

The Golgi has a highly organized and dynamic architecture, comprising a reticulum of linked stacks in the perinuclear regions of cells. The primary function of the Golgi is selective sorting of cargo from the ER that is destined for different cellular locations (Rothman and Wieland, 1996). It also serves as a sensor organelle that recognizes changes in lipid volume and bilayer composition (Maceyka and Machamer, 1997; Wright, 1999). Moreover, various molecules that mediate elaborate cellular signaling pathways are enriched in the Golgi, including caspase-2 (Mancini et al., 2000), protein kinase D (Jamora et al., 1999), phosphatidylinositol 3-kinase (Kihara et al., 2001), enzymes of the ubiquitinproteasome pathway (Hauser et al., 1998), and second messengers (Cockcroft, 1999). The Golgi occupies a central location and represents the center of membrane trafficking within cells. The fact that it also harbors varied resident signaling molecules prompted Mancini et al. (2000) to postulate that the Golgi is the primary information-processing organelle within the cytoplasm. AIGP1 is localized at the Golgi in neurons, and expression is induced specifically by both ER-Golgi stress and axotomy. Given that overexpression of AIGP1 increases the frequency of cell death, this protein may represent a sensor protein for ER-Golgi stress in axotomized neurons. Overexpression of the stress sensor may result in increased stress sensitivity, which in turn accelerates programmed cell death.

In the mouse hypoglossal nerve injury model used in this study, neuronal death occurs gradually over $30 \mathrm{~d}$ and eventually leads to a death rate of $70-80 \%$, and various cell death-associated genes are induced in hypoglossal nuclei (S. Seo-Kiryu, R. Kato, T. Hirayama, and H. Kiyama, unpublished observations). Furthermore, cell death of axotomized motoneurons was also indicated in a rat hypoglossal nerve injury model (Baba et al., 1999). Most evidence suggests that axotomy-induced cell death is caused by activation of mitochondrial cell death signaling. In fact, increased expression of $\mathrm{BH} 3$ protein family members such as Bim and translocation of Bax to the mitochondrial membrane have been demonstrated after nerve injury (Putcha et al., 2001). Among the major findings of our study are that ER-Golgi stress may be elicited after axotomy and involved in the mechanism of cell death. The exact relationship between axotomy and the cooccurrence of ER-Golgi stress is unknown. However, the Golgi may be one of the primary organelles affected by stress derived from transection of the axon because axotomy interrupts part of the membrane as well as vesicular trafficking from the Golgi complex to the axon. Furthermore, the substantial and immediate reorganization of protein synthesis for both survival and death in response to axotomy gives rise to severe stress in the ER-Golgi system.

\section{REFERENCES}

Abeijon C, Hirschberg CB (1992) Topography of glycosylation reactions in the endoplasmic reticulum. Trends Biochem Sci 17:32-36.

Aoki K, Sun YJ, Aoki S, Wada K, Wada E (2002) Cloning, expression and mapping of a gene that is upregulated in adipose tissue of mice deficient in bombesin receptor subtype-3. Biochem Biophys Res Commun 290:1282-1288.

Baba N, Koji T, Itoh M, Mizuno A (1999) Reciprocal changes in the expression of $\mathrm{Bcl}-2$ and $\mathrm{Bax}$ in hypoglossal nucleus after axotomy in adult rats: possible involvement in the induction of neuronal cell death. Brain Res 827:122-129.

Cameron AA, Cliffer KD, Dougherty PM, Willis WD, Carlton SM (1991) Changes in lectin, GAP-43 and neuropeptide staining in the rat superficial dorsal horn following experimental peripheral neuropathy. Neurosci Lett 131:249-252.

Cockcroft S (1999) Mammalian phosphatidylinositol transfer proteins: emerging roles in signal transduction and vesicular traffic. Chem Phys Lipids 98:23-33.

Doan A, Thinakaran G, Borchelt DR, Slunt HH, Ratovitsky T, Podlisny M, Selkoe DJ, Seeger M, Gandy SE, Price DL, Sisodia SS (1996) Protein topology of presenilin 1. Neuron 17:1023-1030.

Easton DP, Kaneko Y, Subjeck JR (2000) The hsp110 and Grp1 70 stress proteins: newly recognized relatives of the Hsp70s. Cell Stress Chaperones 5:276-290.

Fu SY, Gordon T (1997) The cellular and molecular basis of peripheral nerve regeneration. Mol Neurobiol 14:67-116.

Goldberg JL, Barres BA (2000) The relationship between neuronal survival and regeneration. Annu Rev Neurosci 23:579-612.

Grossman TR, Luque JM, Nelson N (2000) Identification of a ubiquitous family of membrane proteins and their expression in mouse brain. J Exp Biol 203:447-457.

Hart GW (1992) Glycosylation. Curr Opin Cell Biol 4:1017-1023.

Hay JC, Chao DS, Kuo CS, Scheller RH (1997) Protein interactions regulating vesicle transport between the endoplasmic reticulum and Golgi apparatus in mammalian cells. Cell 89:149-158.

Hauser HP, Bardroff M, Pyrowolakis G, Jentsch S (1998) A giant ubiquitin-conjugating enzyme related to IAP apoptosis inhibitors. J Cell Biol 141:1415-1422.

Jamora C, Yamanouye N, Van Lint J, Laudenslager J, Vandenheede JR, Faulkner DJ, Malhotra V (1999) Gbetagamma-mediated regulation of Golgi organization is through the direct activation of protein kinase D. Cell 98:59-68.

Kihara A, Kabeya Y, Ohsumi Y, Yoshimori T (2001) Beclinphosphatidylinositol 3-kinase complex functions at the trans-Golgi network. EMBO Rep 2:330-335.

Kiryu S, Yao GL, Morita N, Kato H, Kiyama H (1995) Nerve injury enhances rat neuronal glutamate transporter expression: identification by differential display PCR. J Neurosci 15:7872-7878.

Kiryu-Seo S, Sasaki M, Yokohama H, Nakagomi S, Hirayama T, Aoki S, Wada K, Kiyama H (2000) Damage-induced neuronal endopeptidase (DINE) is a unique metallopeptidase expressed in response to neuronal damage and activates superoxide scavengers. Proc Natl Acad Sci USA 97:4345-4350.

Kitahara T, Kiryu S, Takeda N, Kubo T, Kiyama H (1995) Upregulation of ferritin heavy chain mRNA expression in the rat skeletal muscle after denervation: detected by means of differential display. Neurosci Res 23:353-360.

Kornfeld R, Kornfeld S (1985) Assembly of asparagine-linked oligosaccharides. Annu Rev Biochem 54:631-664.

Krueger WH, Gonye GE, Madison DL, Murray KE, Kumar M, Spoerel 
N, Pfeiffer SE (1997) TPO1, a member of a novel protein family, is developmentally regulated in cultured oligodendrocytes. J Neurochem 69:1343-1355.

Lebel M, Mes-Masson AM (1994) Sequence analysis of a novel cDNA which is overexpressed in testicular tumors from polyomavirus large T-antigen transgenic mice. DNA Seq 5:31-39.

Lee AS (2001) The glucose-regulated proteins: stress induction and clinical applications. Trends Biochem Sci 26:504-510.

Letourneur F, Gaynor EC, Hennecke S, Demolliere C, Duden R, Emr SD, Riezman H, Cosson P (1994) Coatomer is essential for retrieval of dilysine-tagged proteins to the endoplasmic reticulum. Cell 79:1199-1207.

Maceyka M, Machamer CE (1997) Ceramide accumulation uncovers a cycling pathway for the cis-Golgi network marker, infectious bronchitis virus M protein. J Cell Biol 139:1411-1418.

Mancini M, Machamer CE, Roy S, Nicholson DW, Thornberry NA, Casciola-Rosen LA, Rosen A (2000) Caspase-2 is localized at the Golgi complex and cleaves golgin-160 during apoptosis. J Cell Biol 149:603-612.

Morita N, Kiryu S, Kiyama H (1996) p53-independent cyclin G expression in a group of mature neurons and its enhanced expression during nerve regeneration. J Neurosci 16:5961-5966.

Munro S (1995) An investigation of the role of transmembrane domains in Golgi protein retention. EMBO J 14:4695-4704.

Munro S, Pelham HR (1987) A C-terminal signal prevents secretion of luminal ER proteins. Cell 48:899-907.

Nagao M, Nakamura M, Oka N, Akiguchi I, Kimura J (1994) Abnormal glycosylation of motor neurons with $N$-acetyl-D-galactosamine in a case of subacute motor neuronopathy associated with lymphoma. J Neurol 241:372-375.

Nakagawa T, Zhu H, Morishima N, Li E, Xu J, Yankner BA, Yuan J (2000) Caspase-12 mediates endoplasmic-reticulum-specific apoptosis and cytotoxicity by amyloid-beta. Nature 403:98-103.

Namikawa K, Su Q, Kiryu-Seo S, Kiyama H (1998) Enhanced expression of 14-3-3 family members in injured motoneurons. Brain Res Mol Brain Res 55:315-320.

Namikawa K, Honma M, Abe K, Takeda M, Mansur K, Obata T, Miwa A, Okado H, Kiyama H (2000) Akt/protein kinase B prevents injuryinduced motoneuron death and accelerates axonal regeneration. J Neurosci 20:2875-2886.

Ohshige-Hayashi Y, Kiyama H (1997) Expression of glycine max (soybean agglutinin) binding molecule in injured motoneurons and its specific localization in the extracellular matrix between injured neurons and microglia. Neurosci Res 27:271-275.

Oppenheim RW (1996) Neurotrophic survival molecules for motoneurons: an embarrassment of riches. Neuron 17:195-197.

Persson H, Ibanez CF (1993) Role and expression of neurotrophins and the trk family of tyrosine kinase receptors in neural growth and rescue after injury. Curr Opin Neurol Neurosurg 6:11-18.

Pettmann B, Henderson CE (1998) Neuronal cell death. Neuron 20:633-647.

Plenderleith MB, Cameron AA, Key B, Snow PJ (1988) Soybean agglutinin binds to a subpopulation of primary sensory neurons in the cat. Neurosci Lett 86:257-262.

Prescott AR, Lucocq JM, James J, Lister JM, Ponnambalam S (1997) Distinct compartmentalization of TGN46 and beta 1, 4-galactosyltransferase in HeLa cells. Eur J Cell Biol 72:238-246.

Putcha GV, Moulder KL, Golden JP, Bouillet P, Adams JA, Strasser A, Johnson EM (2001) Induction of BIM, a proapoptotic BH3-only BCL-2 family member, is critical for neuronal apoptosis. Neuron 29:615-628.

Rothman JE, Wieland FT (1996) Protein sorting by transport vesicles. Science 272:227-234.

Sachs AB (1993) Messenger RNA degradation in eukaryotes. Cell 74:413-421.

Shortland P, Wang HF, Molander C (1999) Distribution of transganglionically labeled soybean agglutinin primary afferent fibres after nerve injury. Brain Res 815:206-212.

Snider WD (1994) Functions of the neurotrophins during nervous system development: what the knockouts are teaching us. Cell 77:627-638.

Tanabe K, Nakagomi S, Kiryu-Seo S, Namikawa K, Imai Y, Ochi T, Tohyama M, Kiyama H (1999) Expressed-sequence-tag approach to identify differentially expressed genes following peripheral nerve axotomy. Brain Res Mol Brain Res 64:34-40.

Tanabe K, Tachibana T, Yamashita T, Che YH, Yoneda Y, Ochi T, Tohyama M, Yoshikawa H, Kiyama H (2000) The small GTP-binding protein TC10 promotes nerve elongation in neuronal cells, and its expression is induced during nerve regeneration in rats. J Neurosci 20:4138-4144.

Wong MH, Saam JR, Stappenbeck TS, Rexer CH, Gordon JI (2000) Genetic mosaic analysis based on Cre recombinase and navigated laser capture microdissection. Proc Natl Acad Sci USA 97:12601-12606.

Wright SD (1999) Toll, a new piece in the puzzle of innate immunity. J Exp Med 189:605-609. 